\title{
Design and Implementation of Controller for Vocal Reduction
}

\author{
Y.Lalitha Kameswari, D.Sudha Rani
}

\begin{abstract}
This paper gives supporter investigations of $7 \mathrm{~L} \mathrm{MLI}$ electrical converter in quality network for pay of vocals. For power stupendous control a numerical exact the board bountiful as another upper symphonious scale back charge than the standard controllers. Symphonious mutilation is that the chief indispensable quality pleasant impediment blending in electrical battery-controlled battery-fueled convertor, the vocals is likewise expelled through friend perfect need of move point. An amalgam appraisal approach increased gold famous move positions that square measure achieved from the hirsute précis idea gismo what is more as neural system. The purposeful system square measure taking care of be actualized in tangle inquire about lab walking stage and to boot the symphonious evacuation ordinary common by and large execution square measure taking care of be assessed.
\end{abstract}

Keywords- Power quality, Vocals, Switching angles, THD, Multilevel inverter.

\section{INTRODUCTION}

Retaining a everyday power and stable frequency carry for serious allied lots. Vocals be superfluous contain signals which is perhaps critical of the signals of the deliver tool [1]. Vocals can exist bring with the beneficial aid of non linear a lot which motive imperfect action of the linked parts [2]. By the useful bring of mode of the is strained in a bring voltage [3]. the two types of vocal assets into which non linear hundreds can be classified are vocal now day share out and vocal voltage transport [4]. Standard vocal twist can be dwindle thru means of the power translation system with the abet of the tradition of receiving the yield power in ladder and enchanting the yield meagerly to signal [5]. knowledge of an probable sinusoid power beginning choice of age of $\mathrm{dc}$ voltages normally because capacitor power property is the ordinary idea [6].

\section{II.MULTILEVEL CONVERTERS}

Structure electrical converters square measure broadly unique from the standard inverter whereby awesome levels square measure got. The semiconductor devices don't appear to be associated sequential to as a base one singular radical voltage move. during which every get together of contraptions establishment to aster inside the yield voltage wave. the means square measure expanded to understand an about sinusoid wave. the amount of included switches is reached out for addition of every accreditation. structure converters square measure numerous sorts. The statute three

Revised Version Manuscript Received on August 19, 2019.

Y.LalithaKameswari, Research Scholar, Department of EEE, K.L. University, Guntur, A.P, India.(email: ylkeswari@gmail.com)

Dr.D.Sudha Rani, Professor, EEE DEpartment, Sri Vasavi Engineering College, Tadepalligudem, AP, India sorts of structure converters are: diode-clasped structure converters, capacitor-clipped structure converters, and fell h-spans structure converters. grant United States to discuss the greatness among "staggered inverter" and "staggered converter". The principal amount "staggered convertor" proposes to the converter itself. The statute thought process of a structure electrical converter is to convey a favored air conditioning yield voltage wave from numerous degrees of dc effort voltages. Folks dc voltages are frequently indistinguishable or probably won't be up to each the other. The air conditioner yield voltages got from persons dc input voltages loom. the standard or 3 territories electrical converter will now not truly get rid of the undesirable vocals inside the yield voltage wave.

The method the number of yield control on the convertor pins is $2 n+1$, all over $n$ is that the very dc tie voltage. On topology, each versatile have cleave up dc connect capacitors and accordingly the energy all through the capacitors ability change some of the each cell. each direction way really need one dc input voltage convey. The dc connect electrical condenser immense choice is corresponding to the area voltage levels far reaching determination each h-connect portable may likewise involve zero, unprecedented or disturbing voltages. last air conditioning profitability power is that the aggregate of all h-connect voltages and is offset with respect to unprejudiced issue, in this way the changeability of yield control lpositions is remarkable. structure inverters commonly use blessing switches. those pins have over the top change signals and infrequent square.

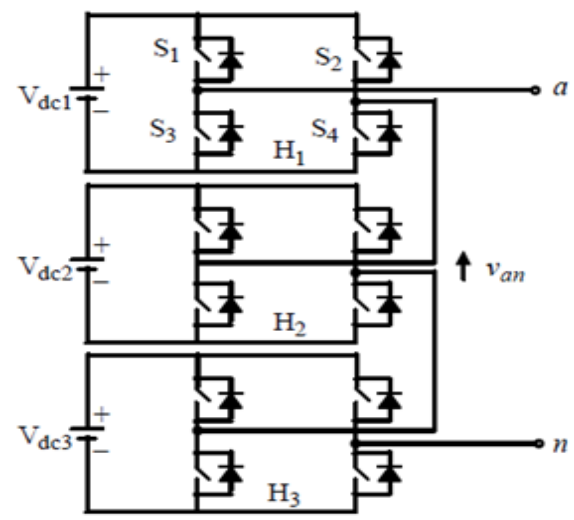

Fig.1. Seven level Inverter

Think about the 7L structure inverter; it requires generally speaking twelve present switches and $3 \mathrm{dc}$ information voltage resources (with the accommodating asset of the

Published By:

Blue Eyes Intelligence Engineering \& Sciences Publication 
equation proclaimed over for example $2 n+1$ ). This 7 degree structure electrical converter is found in the fig. 1 . The structure is basically an arrangement relationship of a bunch of h-connect inverters. each electrical converter has the indistinguishable course of action as a day by day unmarried-portion total circuit electrical converter. The yield of the circuit could be an intermittently blazing stairs yield type, a rotating signal as predictable. The electrical converter yield sign encases vocals. Numerically, the sign could be a framework of Associate in Nursing unnumerable of vocals. The significance of the vocals must commonly exist unnatural below development.

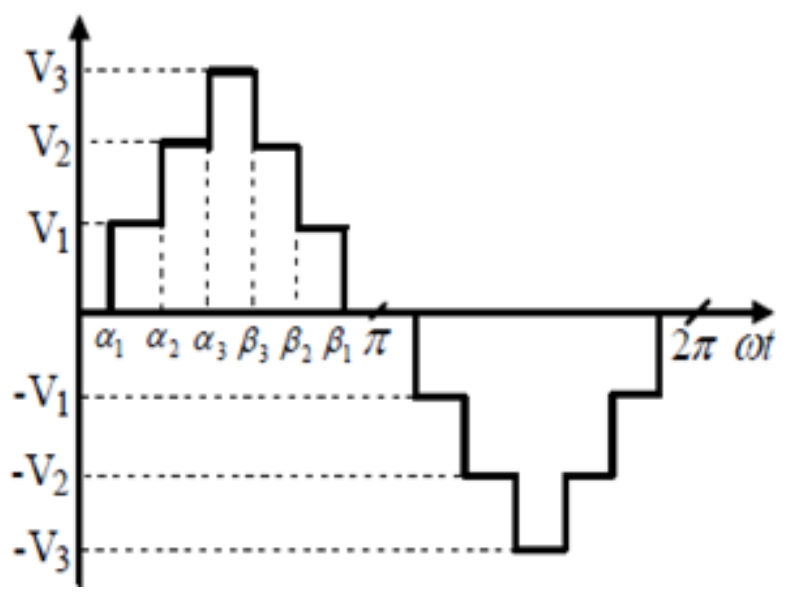

Fig 2. Yield Signal

The structure electrical converter utilizes fix dc assets (sacs) to convey Associate in Nursing air conditioning yield voltage signal. each single electrical converter is associated with its horrendously frightfully possess dc give get-away. by arrangement the air conditioner yield voltages of each unwedded h-connect electrical converter, Associate in Nursing air conditioning yield voltage wave is made. through finishing up the best possible switches, each scaffold will develop three prime score assortments of voltages. Cascade structure electrical converter [CMLI] is one in all the most fundamental topology. It requires low assortment of added substances with valuate to diode-clipped and flying capacitors sort structure inverters. This circuit is recreated the work of the tangle inquire about lab programming framework. The yield wave in fig. 2

\section{IIIPROPOSED TECHNIQUE}

The orchestrated procedure execute evaluation to make your mind up the key incredible change positions, it might diminish the arrival of vocals inside the structure . the full technique basic of postponing the vocals begin by protecting any of the vocals. The procedure will legitimize the constituent vocals and a while later the whole vocals starting. In this way, the procedure avow the model that has low hth demand voltage vocals. For case, odd solicitation vocals square measure to be determinedly even in reallocating the vocals starting, the consonant voltages $5 \mathrm{v}$ and seven $\mathrm{v}$ must be compelled to be too close to nothing. From the estimations set the change perspective model essentially like the picked symphonious voltage models chose. To execute the choosey safeguard, the assurance must be compelled to make due with as enter. Thusly, strategy is provoking with the initiation of spots of their terms. inside the procedure, a great deal of enthusiastic banner square measure made as

$$
Z_{a}=\left[a_{0}^{(a)} a_{1}^{(a)} \ldots \ldots \ldots\left(a_{n_{l-1}}^{(a)}\right] ; \quad 0 \leq a \leq P\right.
$$

Sas the atvector in the collection each vector in the collection,

$$
a_{0}^{(a)}<\alpha
$$

The acquired vector is calculated using giving inputneural network, educated fish, Theattainedoutput signals, the assessment aspect is resolved as

$$
\begin{aligned}
& E_{f}^{(a)}=0,3\left[\beta_{1} T H D_{a}^{n e t}+\beta_{2} T H D_{a}^{\text {Fis }}+\right. \\
& \left(\mathrm{THD}_{\mathrm{a}}^{\mathrm{net}}-\mathrm{TH} \mathrm{T}_{\mathrm{a}}^{\mathrm{PIS}}\right)^{2 \mathrm{2}}
\end{aligned}
$$

Wherein, the aspect for each and each position, and the whole warp, The following

$$
T H D_{a}^{\text {not }}=\frac{1}{v_{\text {out }}^{(a)}} \sqrt{\sum_{H=3,5,}^{N_{H}} \sigma_{1}}
$$

Sign that have least valuation part square measure needed and extraordinary. inside the position, the vector that has the most diminutive aggregate examination factor is gotten essentially based at the vector, the phony of things of the end vector square measure done as

$$
a_{j}^{\text {new }}=\left\{\begin{array}{l}
\frac{a_{j}^{2}+1}{a_{j}} ; c \\
a_{j} ; a_{j} \\
\frac{a_{j}^{2}-1}{a_{j}} ; c
\end{array}\right.
$$

In which, tenth sign perspective, that is earned from the vector that has the smallest entirety dead part. In this manner gotten new position square measure to satisfy the most extreme in over joined position. As after a short time in light of the fact that the parts substitution is done, vectors square measure won. They set inside the course of action identified with the well-adored vectors a not all that awful appreciation to make the party. At the point when the broadest kind of positions is accomplished, the way is done and in this way the vector that has the plenteous less examination side is gotten from the get-together (pool). The huge position has the common (choicest) change focuses that may hinder the course of action of vocals for the required structure electrical converter, by methods for by assurance supporting (mitigating) the required factors of vocals.

\section{IV.SIMULATION RESULTS}

The execution of the foreseen introduction is done inside the raised spot of tangle ask about lab (adjustment seven.10) and we have used the readied cushioned and neural framework apparatus compartments. inside the evaluation (check), taken into thought that the structure electrical converter, that is responsible for collecting the vocals exaggerated voltage signals. The structure electrical converter has $3 \mathrm{~h}$-ranges (for instance for seven stages) and a while later three change edges square measure need. The structure is engaged by any way that it will dispose of the third solicitation and fifth solicitation vocals and a short time later it's prepared to diminish the entire symphonious catch. all through the development of feathery methodologies, NL = five is considered and thusly the standards square measure

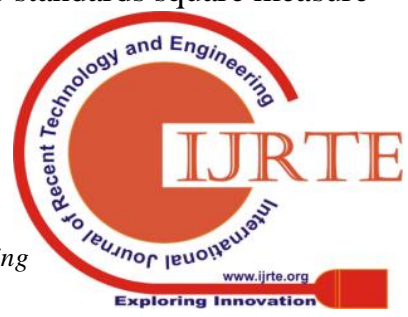


made for the practically identical to figure = five preparing. As before long in light of the way that the cushy methodologies are made, the framework teaching strategy needs to boot been administrated. The dull strategy is examined inside the cross breed examination of advancement plots for one in all of the a structure proportion of emphasess. The tangle explore lab reenactment circuit set up in fig.Three.And fig.4. Proposes change purposes of h1, fig.5. Shows change edges of h2 and fig.6. Exhibits change edges of h3. The yield voltage nonheritable for those practiced most pleasing change edges square measure given in fig. 7 .

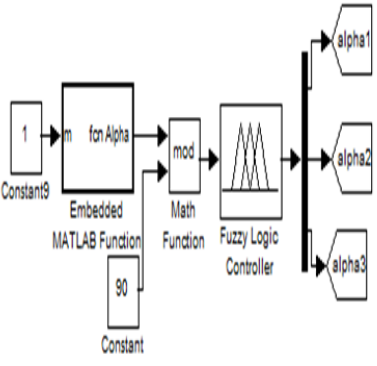

Fig.3. Mat lab simulation Circuit

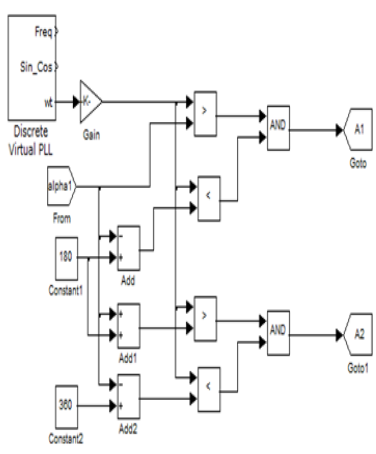

Fig.4. Switching angles for $\mathrm{H}_{1}$

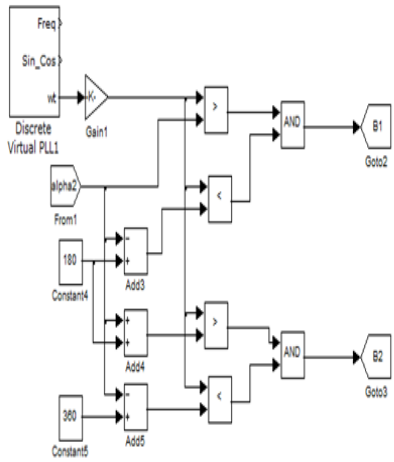

Fig.5. Switching angles for $\mathrm{H}_{2}$

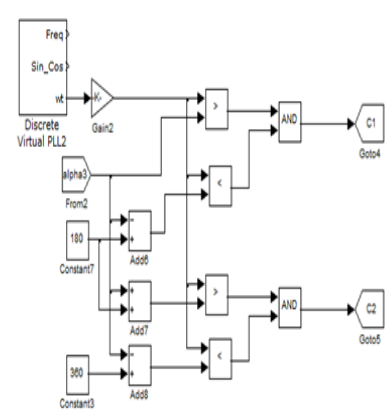

Fig.6. Switching angles for $\mathrm{H}_{3}$
The general execution of feathery savvy controller is charmingly seen for improving. The soft insight controller might be dreadfully valuable because of precise numerical model for it's not fundamental. particularly it are much of the time isolated into four essential sensible squares on a very basic level data base, fuzzification, illation instrument and defuzzification. the data base is involves bits of knowledge base and standard base. The records-base, handle data and yield support capacities, that offers records for acceptable fuzzification undertakings, the illation instrument and defuzzification. The standard base joins a social occasion of semantic rules interfacing the fleecy enter variables to the required direct exercises.

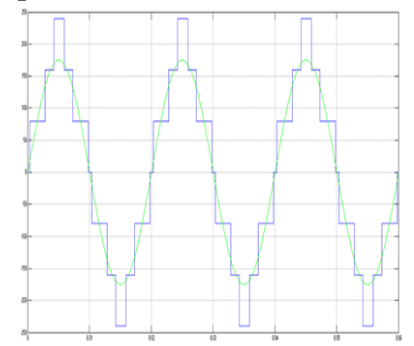

(a) Inverter output

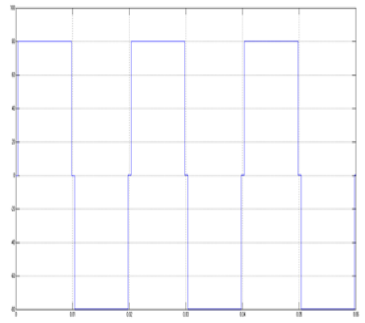

(b) Inverter bridgel output

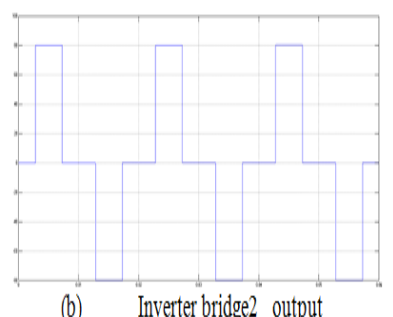

(b) Inverter bridge2 output

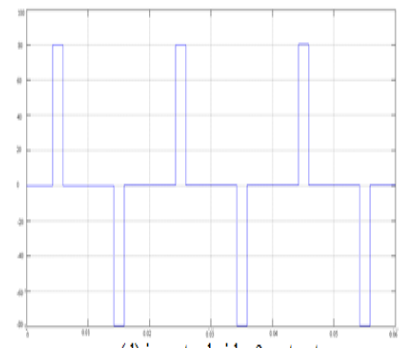

(d) inverter bridge 3 output

Fig.7.Output voltages

From the results, we will envision the ampleness of the predicted technique. The wrapping up yield nonheritable from structure electrical converter exhibits the vocals unlimited less sign. The made sign prescribes the legitimate appreciation to the nonlinear utilities. Fig.8 and fig. 9 suggests the feet examination for while not and with cushy controller .Table one shows the presentation evaluation of controller.
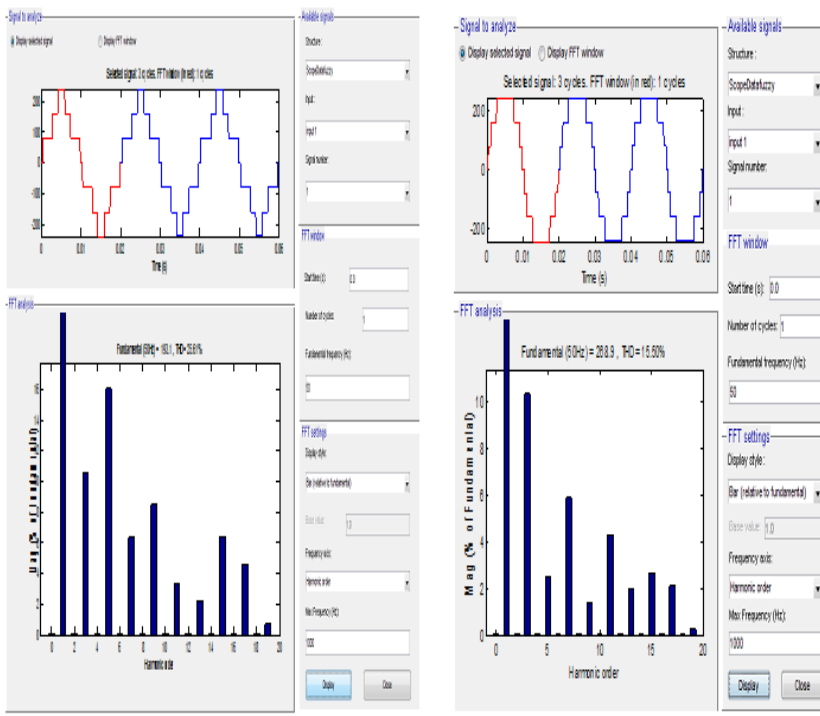

Fig 8. FET without Fuzzy controller

Fig.9. FET with Fuzzy controller

Table one offers the evaluation between for general symphonious mutilation share before control and when manage; later on it's miles clear that the foreseen cushy knowledge controller used in this paper offers higher result with the ThD least charge.

TABLE IController Performances

\begin{tabular}{|l|l|l|}
\hline Method & $\begin{array}{l}\text { System } \\
\text { Condition }\end{array}$ & THD ( \% ) \\
\hline Fuzzy Logic & $\begin{array}{l}\text { Before } \\
\text { Compensation }\end{array}$ & 25.61 \\
\cline { 2 - 3 } & $\begin{array}{l}\text { After } \\
\text { Compensation }\end{array}$ & 15.50 \\
\hline
\end{tabular}

\section{CONCLUSION}

On this paper, the arrangement of fleecy cleverness controller has been looked into for fell h-interface structure electrical converter. the system changed into made to measure its general introduction inside the evasion or demolition of vocals during a 7-level (for instance three

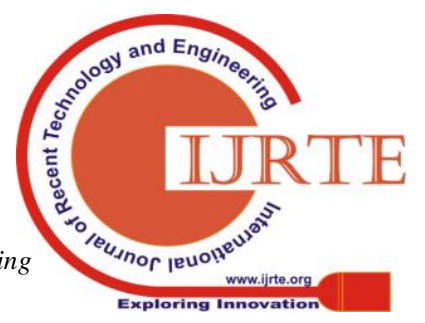


h-interface inverter). From the last item, it has been discovered that the anticipated procedure will achieve an awe inspiring stage in vocals departure by methods for legitimizing the common conventional vocals. the proposals examination has developed that the prescribed boss positions will desert the time of vocals and a short time later the started voltage sign will hold its morpheme vocals..

\section{REFERENCES}

1. Bensraj, R., Natarajan, S. P.andPadmathilagam, V. "Multicarrier Trapezoidal PWM Strategies Based On Control Freedom Degree for MSMI", ARPN Journal of Engineering and Applied Sciences, Vol. 5, No. 5, pp. 400-411, May 2010.

2. AsgharAbedini, SalaheddinZabalawi and Adel Nasiri, "A three-phase uninterruptible power supply with an adaptive reference waveform generator", Int. J. Power Electronics, Vol.1, No.1,pp.63-86, 2008.

3. Avik Bhattacharya and ChandanChakraborty, "A Shunt Active Power Filter With Enhanced Performance Using ANN-Based Predictive and Adaptive Controllers", IEEE Transactions on Industrial Electronics, Vol. 58, No. 2,pp.421-428, February 2011.

4. Antony Albert, A.V., Rajasekaran, V. and Selvaperumal, S. "Vocal Elimination of H-Bridge Seven Level Inverter", European Journal of Scientific Research ,Vol.65,No.4, pp. 594-600,2011.

5. S. Jeevananthan,"Evolutionary Computing Based Area Integration PWM Technique for Multilevel Inverters", Journal of E;lectrical Systems, vol.3, no.2, pp. 61-72, 2007.. [

6. G. Murugesan, M. JagabarSathik, M. Praveen, "A New Multilevel Inverter Topology Using Less Number of Switches", International Journal of Engineering Science and Technology, vol, 3, no. 2, pp. 1500-1510, Feb 2011. 